\title{
Student Surveys And Their Applications In Promoting Academic Quality In Higher Education
}

Nitza Davidovitch, Ari'el University Center, Israel

Dan Soen, Ari'el University Center and Kibbutzim School of Education, Tel-Aviv, Israel

\begin{abstract}
The present study focuses on an examination of the differences in students' ratings of instructors, comparing voluntary and optional survey participation modes. The study hypothesis stated that differences in participation modes may adversely affect the authenticity of assessments, due to concerns that students would retaliate against the mandatory nature of the task. To examine the study hypothesis, we sampled 46,205 student assessments in 2008/9 and 103,164 assessments completed in 2009/2010. The assessments involved 534 instructors who taught the same 1,014 courses in both years. Differences were measured in students' overall ratings of the instructors, course structure and organization, clarity of lectures, instructors' encouragement to ask questions, instructors' attitudes toward students, and correspondence between lectures and tutorials. A significant unequivocal finding to emerge from this study is the absence of any association between the participation mode and students' rating. Findings thus eliminate any concerns regarding lack of authenticity of the assessments in the mandatory participation mode. Due to the importance of student assessments, the academic privilege should be transformed into a requirement to allow academic institutions to evaluate the effectiveness of teaching more precisely.
\end{abstract}

Keywords: student surveys; higher education; quality; teaching evaluations; authenticity

\section{INTRODUCTION}

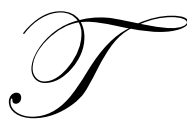

his study, the first of its kind, tracks all students' assessments of instructors at an academic institution in Israel. In recent years, the organizational attitude toward student surveys has changed from a view of the survey as a voluntary opportunity for students to assess their instructors' performance to a serious and significant obligation imposed on students and a duty they have toward their institution.

This policy change demands that academic institutions institute a process of self-control concerning the potential biases of student assessments in academic institutions, in general, and during organizational changes, in particular. Involvement of faculty members in the assessment process is essential and academic institution is an important stratum in developing institutional strategies. Student assessment of instructors constitutes a basis for organizational learning and growth, aligned with an aspiration for academic excellence.

In the past, students completed paper-and-pencil surveys manually, in the classroom, as captives forced to cooperate against their will. As technologies developed, most academic institutions send surveys directly to students' computers and are completed online. In contrast to the handwritten version, the electronic survey requires that academic institutions devise ways to enroll students in the process. Academic institutions attempt diverse methods and creative ideas to motivate students to complete the surveys, including sweepstakes with prizes such as scholarships, cars, vacation packages, and the like. None of these, however, have successfully induced students to devote their precision time to this task, and response rates have remained low despite material temptations. 
In view of the importance of student surveys and the poor online response rates (25\%-35\%), the University Center of Samaria decided to define completion of the student survey as one of students' numerous academic requirements.

This organizational change was accompanied by concerns and criticism on part of students and instructors both, who argued that coercion would adversely affect the authenticity of the ratings. The purpose of the current study is to test these claims by examining potential biases in students' ratings in view of the organizational change described above. Specifically, we seek to examine whether ratings are linked to the organizational procedure to which they are tied. In other words, do student ratings differ significantly when participation in the survey is voluntary or mandatory?

\section{Students' Assessments of Academic Institution - Right or Obligation}

Students' assessments of instructors were first introduced in the academe in the early $20^{\text {th }}$ century, but the rise in their status and importance occurred only in the 1970s (Hativa, 2008). Over time, these surveys gained recognition as an economical and efficient tool for assessing the effectiveness of teaching and a means of drawing practical conclusions related to improvement in the quality of teaching and assessment of instructors' performance. The use of student surveys is most prevalent in the USA and Canada, where much importance is attributed to transforming teaching into an occupation of professional status and determining rigid criteria of knowledge and skills necessary in teaching (Hativa 2002, 2003). Assessment surveys are considered a means to achieving these goals and have also led European countries to adopt the assessment method, despite the debate over the use of survey results as a valid measure in operational decision-making (Reinderman \& Schofield, 2001).

In the first years of implementation of the surveys, they were used as a feedback instrument of no farreaching consequences. However, over the years, they were no longer considered purely as a feedback tool that offers recommendations for improvements, but rather as a tool whose results have significant implications for academic career decisions including tenure, promotions, and appointments (Ehie \& Kararthanos, 1994; Harrison, et al., 2004; Smith \& Pollak, 2008).

These aspects inevitably affect salaries, perceived prestige, and employment opportunities. Survey results gain great importance and provide a measure for officials. The dominance of surveys, also called the "assessment mandate" (Chandler, 1978), dictates and considerably determines instructors' career paths. These implications have made assessment surveys a target for criticism of faculty and the topic of many studies that have sought to examine the reliability and validity of assessment surveys and the extent to which students should be given the power to influence the careers of academic scholars. Opinions are divided into advocates and opponents. Some have stated that this debate is the most serious debate in the field of teaching research (Chandler, 1978).

On one side of the divide are those who view the surveys as a judgmental tool that undermines instructors' academic status and places instructors in an inferior position that is imposed from the outside (Avador, 2006). Advocates of this approach believe that instructors should "deliver the goods" to the students and students should award them points for performing. This perspective is typically the result of a lack of dialogue between instructors and their supervisors, among instructors, and between instructors and their students (Avador, 2006). On the other side of the divide are those who support the use of the surveys and recognize their significance as a means to promote and improve the quality of instruction and satisfaction of students-clients (Marsh, 1987; Marsh \& Roche, 1994).

Stanley Fish is a vehement opponent against treating student assessments of their faculty seriously as a means for evaluating the quality of work of teachers in higher education. He recently wrote:

...that is why student evaluations (against which I have inveighed since I first saw them in the '60s) are all wrong as a way of assessing teaching performance: they measure present satisfaction in relation to a set of expectations that may have little to do with the deep efficacy of learning. Students tend to like everything neatly laid out; they want to know exactly where they are; they don't welcome the introduction of multiple perspectives, especially when no master perspective reconciles them; they want the answers. 
But sometimes (although not always) effective teaching involves the deliberate inducing of confusion, the withholding of clarity, the refusal to provide answers; sometimes a class or an entire semester is spent being taken down various garden paths leading to dead ends that require inquiry to begin all over again, with the same discombobulating result; sometimes your expectations have been systematically disappointed. And sometimes that disappointment, while extremely annoying at the moment, is the sign that you've just been the beneficiary of a great course, although you may not realize it for decades.

Needless to say, that kind of teaching is unlikely to receive high marks on a questionnaire that rewards the linear delivery of information and penalizes a pedagogy that probes, discomforts and fails to provide closure. Student evaluations, by their very nature, can only recognize, and by recognizing, encourage assembly-line teaching that delivers a nicely packaged product that can be assessed as easily and immediately as one assesses the quality of a hamburger (Fish, 2010).

But, J. Priestly, one of the posters responding to the article, retorted:

So, the consumer of a $\$ 30,000 / y e a r(+-20 K)$ service should not have a strong voice in evaluating the service? Absolutely students should have a chance to provide their feedback! I am surprised to see all of the supportive comments for this article from a readership that demographically should be supporters of market-driven school choice and increasing teacher quality. The provider of the service (the college) absolutely should seek that feedback. How it chooses to seek that feedback and what it chooses to do with that feedback is more a matter of judgment, and product positioning. A smart college will collect and analyze and act upon the realities that are depicted, while recognizing that a segment of its consumers just want easy A's (and decide whether or not to cater to that segment or not).

A good professor will sigh at the injustices and learn from the balanced feedback, and still get better. Hopefully the poor professors will get better, or perhaps the college will act to improve the level of service. The unfair slings and arrows will average out. It's true that few others in life have to put up with such public review of their work, but frankly when we provide a service to others, we should expect that they will share their experience, not cover up our faults so the others don't find out. We should have to face public comments on our work as teachers, administrators, doctors, plumbers, etc. In such an environment, we'd all recognize there are also all sorts in the world, so a certain amount of discounting is required - and perhaps a certain amount of self-improvement also.

The information will guide students. Students seeking guts will learn to dodge those courses excessively challenging, and students seeking challenge will know how to read the comments of others (this is why it is important that the comments of student reviewers also get published). Any professor who thinks they are providing a high quality service and whose ratings persist as low needs to learn to better describe their course to divert students seeking less challenge and also needs to wonder whether the "high quality" teaching is really such (Priestly, 2010).

In the second part of his column, Fish continues:

Others, not from Texas, tell me that the future I predicted as a joke - teachers advertising for customers as if they were shills for a floor show - has already arrived along with the predictable bad consequences. Still others chime in with personal horror stories - the teacher who, after having moved a class to a morning hour in response to student requests, found himself pilloried by those same students for making them get up too early; the teacher who was negatively reviewed by students who had never shown up (they needed to turn in an evaluation in order to get credit for the class they had not attended). Even students joined the chorus, expressing disgust at colleagues who anonymously settle personal grievances or retaliate for low grades by trashing instructors unable to defend themselves. These anonymous and accountability-free reasons, a former professor complains (he is "former" for just this reason), "can destroy a career that took a decade to train for." (vero) They can also lead to the abandoning or blighting of a career. Posters report variously that they left teaching altogether or moved to a foreign country where the "customer" mentality had not yet set in, or they stuck it out for 30 years while becoming ever more bitter and disillusioned. Even those who are aware that there is little correlation between student evaluations and effective teaching (the preponderance of studies document this non-correlation), and therefore 
know that negative comments do not reflect an informed judgment, are nevertheless pained and humiliated by them: "Even though I know this, they always manage to hurt my feelings and reduce my own personal morale" (Sarah). The deleterious effects of student evaluations extend beyond the personal injuries these comments rehearse; they infect the entire system of higher education. Teachers who fear (correctly) that student evaluations will determine their fate become stand-up comedians - wave your arms around, praise students excessively and "dress sharp," advises Dr. Bob - and alter their grading policy in an effort to be liked. Since "student evaluations are driven almost entirely by the perception of grades" (Troglomorphic), grade inflation - "an insidious weed choking out real education" (vince) - "is inevitable." Another poster (A Teacher), noted, "Sorry kids, you are not the authority in the classroom. Me Teacher. You student. Me Teach, You Learn. End of Discussion ... Education is not a business. You are not my customer. My classroom is not Burger King. You do not get to 'have it your way' (Fish, 2010).

Despite the debate and the numerous opponents arguing against such quality assessments, it is accepted that education should strive toward "effective teaching" by improving the quality of instruction and reducing drop-out rates. Governments and universities develop practices and policies designed to encourage, measure, and reward "good teaching" (Ballentyne et al., 2000). Thus, the debate is not waged over the need to conduct quality control, but rather to the method of its implementation and the extent of its effectiveness. The question thus arises whether the academe's reliance on student assessment is excessive. Are the surveys reliable and valid? Or do the survey results reflect mutual manipulations by students and instructors to obtain higher grades and ratings, respectively?

Many faculty members argue against the surveys (Hativa, 2008), claiming that surveys are biased for a number of reasons, including issues that are not under the control of instructors, such as course features including level of difficulty and scope of material covered (Chen \& Hoshower, 1998; Feldman, 1978; Wachtel, 1998); instructors' traits, such as external appearance, gender, age, and ethnic origin (Anderson \& Siegfried, 1997; Wachtel, 1998); students' traits, such as individual expectations, gender, motivation, attendance (Anderson \& Siegfried, 1997; Chen \& Hoshower, 1998; Davidovitch, \& Notzer, 2004; Koermer \& Petelle, 1991; Tatro, 1995;); and administrative features, such as classroom size and course schedule (Chen \& Hoshower, 1998; Feldman, 1978; Wachtel, 1998).

Each of these factors is a potential cause of bias that might affect an instructor's performance rating, as teaching is not a context-free practice and the instructor's abilities and skills cannot be isolated from other factors that participate in the student-instructor-classroom interaction. Therefore, there is a degree of logic in the statements of faculty members who do not view students' opinions as an effective method of assessing the quality of their work, a fortiori, as a means of determining their future career.

In the current study, we sought to examine the impact of an organizational change using a case study of the Ariel University Center of Samaria, which modified the status of student surveys of instructors from a voluntary to a mandatory task. We sought to examine whether differences in students' assessments exist and examine the association between assessments and the underlying organizational process.

\section{The Organizational Process}

Students' surveys of teaching for the fall semester 2008/2009 were posted on December 24, 2008, and closed on January 17, 2009. This year, student surveys were held pursuant to a resolution of the Central Committee dated August 5, 2009, stating that "Students are obligated to complete surveys of teaching. Students who fail to complete the survey will not be allowed to take the exam." As a result, students received a request to participate in the survey and complete a questionnaire for every course in which they are registered.

Students were informed that the assessment of instructors, previously optional, was now mandatory:

1. "Yes, your opinion is important to us."

2. For you, completing the survey is an opportunity to assess the level of instruction of the academic faculty and the standards of service you receive from the administrative faculty in the department in which you are 
enrolled. For us, this is a tool to promote, improve, and enhance the efficiency of the system. The survey is very important for us and for the students. The University Center monitors faculty members' success in teaching and the survey results are a most important tool in determining academic appointments, promotions, and tenure decisions, and in referring them to training conducted by the Academic Development Unit, which focuses on improving academic quality.

3. We are committed to anonymity and full confidentiality of the respondents. There is no way to identify a respondent from his responses to the questionnaire.

4. You have the option of responding to the questions of your choice.

5. The privilege and duty to influence teaching.

6. To allow us to make reliable and valid use of the survey results, it is very important that as many students as possible participate in the survey. Assessments in courses with low student response rates are not taken into consideration in administrative decisions concerning instructors' employment and promotion. Therefore, for students to have a say in this, the majority should respond to the survey.

7. This is the reason the Senate decided that students are obligated to complete the survey and students who fail to do so are not allowed to sit for the examination. We would like to avoid any unpleasantness and avoid students being forced to complete the surveys at the expense of their exam time. At the Ariel University Center, we invest considerable efforts in the interests of students by offering scholarships, financial aid, tuition payments in exchange for community service, test accommodations for students with special needs, and many other actions. Therefore, we expect our students to devote their time to complete a survey for each course in which they are registered. We see this as both a privilege and an obligation.

Following the explanation of the organizational rationale, students were given clear instructions on how to access the website and complete the survey.

The process was completed in three weeks. During this period, reminders were sent to students who failed to submit a survey. Deans, department heads, and faculty members also received explanations of the process. The process was discussed in faculty meetings. For example, faculty members received a note stating, "We would appreciate your assistance in encouraging the students to participate in the survey, which is part of the University Center's policy to foster an institutional culture of assessment and quality. We appreciate your cooperation."

Efforts were invested to create an organizational process that encouraged involvement and was comprehensive. We expected all units of the University Center to assume a role in the efforts to inform students, since we expected opposition to the requirement we imposed on the students, notwithstanding the "soft" explanations we gave.

Furthermore, we informed both students and faculty members that the survey results would be made public and a list of outstanding faculty members, adjunct instructors, and tutors in each department and faculty would be published.

On the backdrop of this organizational process, we conducted the assessment study reported in this paper. In the 2009-2010 academic year, survey participation was optional, but in the 2010-2011 academic year, students were required to complete a survey for each course in which they are enrolled. The aim of the study is to examine the argument expressed by students and faculty members claiming that instructor ratings are related to the nature of the survey. In other words, students who are required to assess the performance of their instructors, against their will, will "take revenge" by refusing to treat the survey with due seriousness, make comments, and express their opposition to the mandatory nature of the task, ultimately awarding lower scores to instructors.

As noted, the topic of instructor assessment is a well-studied issue in the field of assessment methods. There are more than 2,000 studies in the ERIC database alone (Centra, 2003) on this topic. However, despite their 
abundance, most studies are generic and do not focus on specific traits in the teaching setting. These studies mainly examine teaching from a universal, inter-disciplinary perspective (Hativa 2003a). This point is of great importance as focusing on a specific field of knowledge or discipline allows us to extend the empirical significance of the studies (Worthington, 2002).

As an added advantage to the present study, we distinguish between the various faculties and analyze students' responses to each of the survey items separately - overall assessment of the course instructor, assessment of course structure and organization, assessment lecture clarity, assessment of the extent to which instructors encourage students to ask questions, and assessment of the extent of correspondence between lectures and tutorials.

Furthermore, the scope of the present study is considerable. The study is based on 46,025 assessments of instructors and courses in 2008-2009 (24,059 in the fall semester and 21,966 in the spring semester), and 103,164 assessments in 2009-2010 (53,103 and 50,061 in the fall and spring semesters, respectively). To compare these two years and control for specific course and instructor effects, we included only assessments for instructors who taught the same courses in both years. Since some courses are taught both in the fall and the spring semesters, data were organized on an annual rather than semester basis. Data analysis is based on assessments pertaining to 534 instructors who taught a total of 1,104 courses, offered in both study years by the same instructor. For each instructor, we examined differences in the number of surveys completed, the overall course assessment, the assessment of course structure and organization, lecture clarity, instructor's encouragement of students to ask questions, instructor's attitude to the students, and the correspondence between lectures and tutorials.

\section{Study Design}

To examine the differences in students' assessments of instructors as a function of the nature of the survey (optional or mandatory) in a case study of the Ariel University Center (AUC), we examined the associations between these variables using data collected in student surveys. However, since these surveys are anonymous, services of an external company (Rensys) were used to match students' assessments with their course grades. The researchers accessed anonymous and collective data only. Students were informed in advance that their identity would be protected and any use of the survey data would be anonymous.

\section{Statistical Analyses}

To examine differences by year and faculty, two-way ANOVA tests were performed on each variable, with repeat measures for academic year.

\section{FINDINGS}

\section{Comparison Of Findings By Year}

As shown in Table 1, 44.2\% of the surveyed courses are in the Faculty of Social Studies and Humanities, $25.9 \%$ are in the Faculty of Engineering, $16.3 \%$ are in the Faculty of Health Studies, $7.4 \%$ in Natural Sciences, and $6.2 \%$ of the courses are in the School of Architecture. These ratios reflect the relative size of each faculty, based on the number of students enrolled in each.

Table 1: Distribution Of Surveyed Courses By Faculty In 2008/2009 And 2009/2010

\begin{tabular}{|l|c|c|}
\hline Faculty & $\mathbf{N}$ & $\%$ \\
\hline Social Science and Humanities & 624 & $\% 44.2$ \\
\hline Engineering & 365 & $\% 25.9$ \\
\hline Health Sciences & 230 & $\% 16.3$ \\
\hline Natural Sciences & 104 & $\% 7.4$ \\
\hline Architecture & 88 & $\% 6.2$ \\
\hline Total & 1411 & $\% 100$ \\
\hline
\end{tabular}


As seen in Table 1, the relative increase in the number of courses and students enrolled in each faculty is reflected in the significant differences found by academic year $\left(\mathrm{F}(1,1406)=585.82, \mathrm{p}<0.001, \eta_{\mathrm{p}}{ }^{2}=0.29\right)$. It is therefore not surprising that the average number of assessments per instructor in 2008/2009 is smaller compared to 2009/2010. Differences in the number of comments added to the surveys were also found by faculty $\left(\mathrm{F}(4,1406)=24.17, \mathrm{p}<0.001, \eta_{\mathrm{p}}{ }^{2}=0.06\right)$ and in the interaction of academic year and faculty $(\mathrm{F}(4,1406)=8.21, \mathrm{p}<0.001$, $\left.\eta_{\mathrm{p}}{ }^{2}=0.02\right)$. Figure 1 depicts the results.

Table 2: Means And SD Of Number Of Assessments Per Course By Year And Faculty

\begin{tabular}{|l|c|c|c|c|c|}
\hline \multirow{2}{*}{ Faculty } & \multirow{2}{*}{$\mathbf{N}$} & \multicolumn{2}{|c|}{$\mathbf{2 0 0 8 / 2 0 0 9}$} & \multicolumn{2}{|c|}{$\mathbf{2 0 0 9 / 2 0 1 0}$} \\
\cline { 3 - 6 } & & $\mathbf{M}$ & $\mathbf{M}$ & $\mathbf{M}$ & \multicolumn{1}{c|}{ SD } \\
\hline Architecture & 88 & 12.38 & 7.20 & 30.16 & 25.52 \\
\hline Health Sciences & 230 & 14.81 & 10.37 & 36.75 & 25.21 \\
\hline Engineering & 365 & 17.14 & 12.49 & 38.95 & 26.20 \\
\hline Social Sciences and Humanities & 624 & 22.75 & 17.74 & 49.84 & 38.33 \\
\hline Natural Sciences & 104 & 15.03 & 10.81 & 29.91 & 21.04 \\
\hline Total & 1411 & 18.79 & 14.91 & 42.19 & 32.07 \\
\hline
\end{tabular}

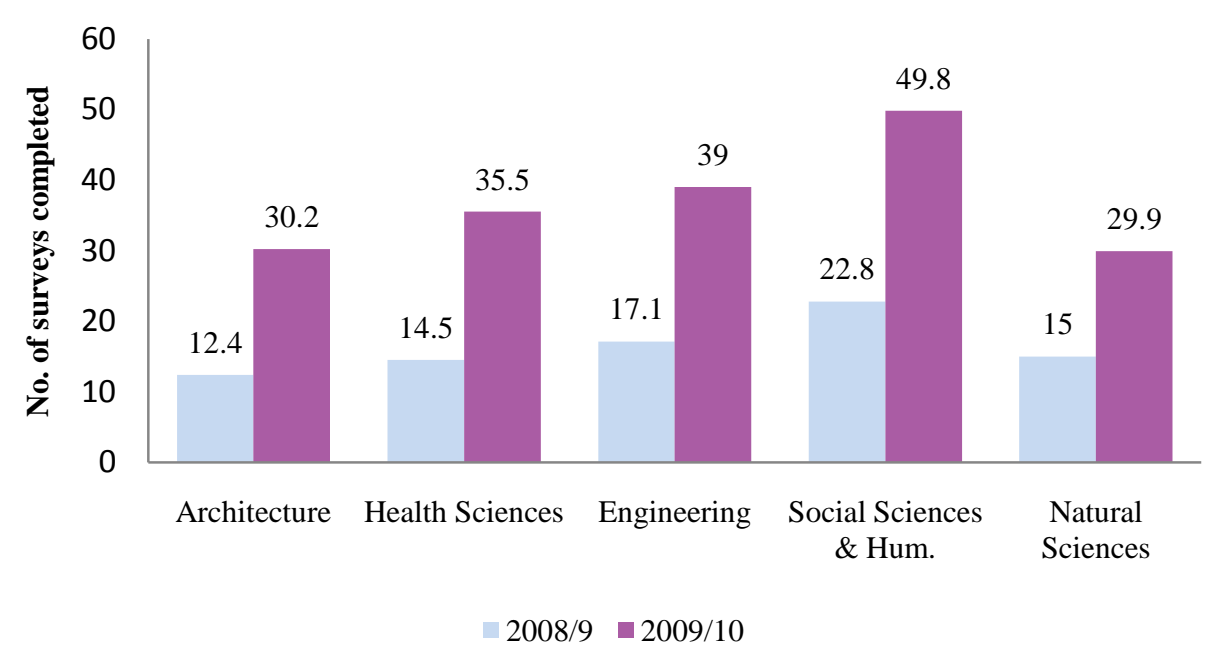

Figure 1: Interaction of Number of Assessments per Course by Year and Faculty

As evident from Table 2, one significant advantage of the scope of operations of the faculties is, as noted above, also expressed in the average number of assessments in the Faculty of Social Sciences and Humanities, which was greater $(M=27.09, S D=30.53)$ than in the School of Architecture $(M=17.78, S D=12.48)$, the Faculty of Engineering $(M=21.80, S D=19.50)$ and the Faculty of Natural Sciences $(M=14.88, S D=16.69)$. No differences in the number of assessments per course emerged in the School of Health Sciences ( $M=21.94, S D=21.42)$. The most important finding is that no significant differences were found in students' assessments by year $(\mathrm{F}(1,1404)=0.88$, $\mathrm{ns})$, and no interaction effect was found by faculty and year $(\mathrm{F}(4,1404)=2.45$, ns). 
Table 3: Means And SD Of Overall Assessment Of Course Instructor By Year And Faculty

\begin{tabular}{|l|c|c|c|c|c|}
\hline Faculty & \multirow{2}{*}{$\mathbf{N}$} & \multicolumn{2}{|c|}{$2008 / \mathbf{2 0 0 9}$} & \multicolumn{2}{c|}{$2009 / \mathbf{2 0 1 0}$} \\
\cline { 3 - 6 } & & $\mathbf{M}$ & SD & M & SD \\
\hline Architecture & 87 & 3.98 & 0.72 & 4.05 & 0.58 \\
\hline Health Sciences & 229 & 4.31 & 0.56 & 4.21 & 0.52 \\
\hline Engineering & 365 & 4.04 & 0.66 & 4.02 & 0.57 \\
\hline Social Sciences and Humanities & 624 & 4.21 & 0.60 & 4.15 & 0.54 \\
\hline Natural Sciences & 104 & 4.04 & 0.66 & 4.08 & 0.59 \\
\hline Total & 1409 & 4.16 & 0.63 & 4.11 & 0.55 \\
\hline
\end{tabular}

Significant differences were found by faculty and year $\left(F(4,1404)=9.84, p<0.001, \eta_{p}{ }^{2}=0.03\right)$. Figure 2 presents the results.



Faculty

Figure 2: Overall Assessment of Course Instructor by Faculty

We examined each survey item and found as shown in Table 3:

1. Table 3 shows that overall assessments of course instructors in the Faculty of Health Sciences were higher than in the School of Architecture, the Faculty of Social Sciences and Humanities, and the Faculty of Natural Sciences. Notably, overall assessments of course instructors were higher in the Faculty of Social Sciences and Humanities than in the School of Architecture, the Faculty of Engineering, or the Faculty of Natural Sciences.

2. As shown in Table 4, no significant differences were found by year or faculty in assessments of course organization and structure $(\mathrm{F}(1,1401)=1.18, \mathrm{~ns})$.

Table 4: Means And SD Of Assessments Of Course Structure And Organization By Year And Faculty

\begin{tabular}{|l|c|c|c|c|c|}
\hline \multirow{2}{*}{ Faculty } & \multirow{2}{*}{$\mathbf{n}$} & \multicolumn{2}{|c|}{$2008 / 2009$} & \multicolumn{2}{c|}{$2009 / 2010$} \\
\cline { 3 - 6 } & & $\mathbf{M}$ & SD & M & SD \\
\hline Architecture & 87 & 3.75 & 0.82 & 3.78 & 0.69 \\
\hline Health Sciences & 227 & 4.23 & 0.61 & 4.10 & 0.57 \\
\hline Engineering & 364 & 3.98 & 0.69 & 3.96 & 0.56 \\
\hline $\begin{array}{l}\text { Social Sciences and } \\
\text { Humanities }\end{array}$ & 624 & 4.12 & 0.65 & 4.08 & 0.55 \\
\hline Natural Sciences & 104 & 3.99 & 0.67 & 4.05 & 0.63 \\
\hline Total & 1406 & 4.07 & 0.68 & 4.03 & 0.58 \\
\hline
\end{tabular}


According to Table 4, no interaction effects emerged by faculty or year. Significant differences emerged by faculty after controlling for year $\left(F(4,1401)=11.33, \mathrm{p}<0.001, \eta_{\mathrm{p}}{ }^{2}=0.03\right)$. Figure 3 presents the results.

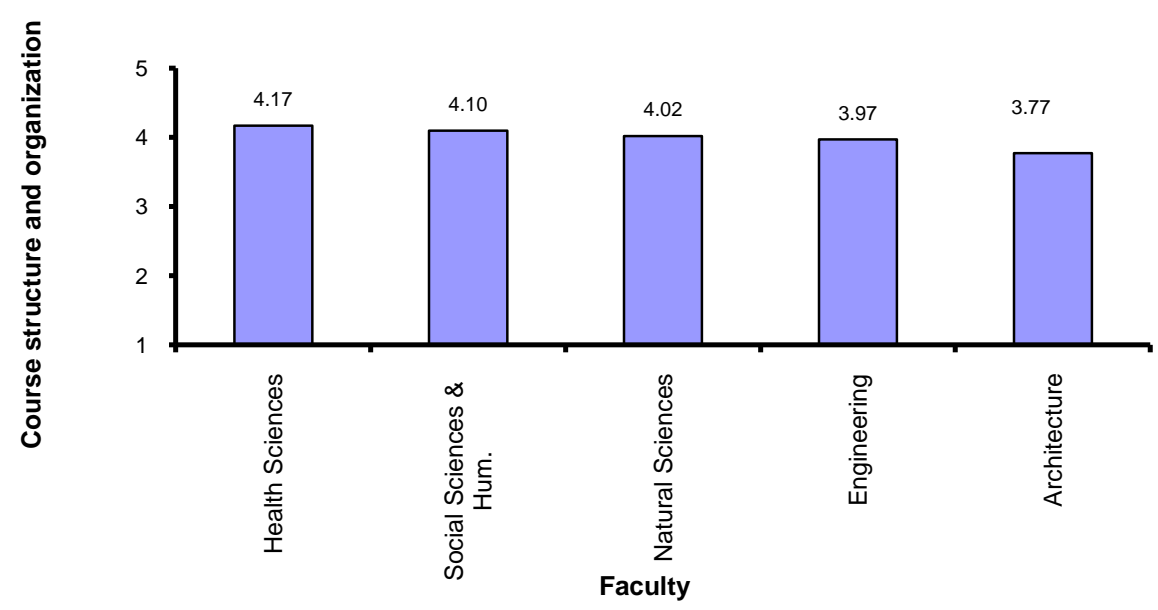

Figure 3: Assessments of Course Structure and Organization by Faculty

Students in the Faculty of Health Sciences awarded higher ratings to course structure and organizations compared to students in the School of Architecture, the Faculty of Engineering, and the Faculty of Natural Sciences. Students in the School of Architecture awarded lower ratings of course organization and structure than the remaining students. Students in the Faculty of Social Sciences and Humanities awarded higher ratings to course structure and organization than students in the Faculty of Engineering.

3. Table 5 shows the differences in lecture clarity by faculty and year. No significant differences were found by year.

Table 5: Means And Sd Of Assessments Of Lecture Clarity By Year And Faculty

\begin{tabular}{|l|c|c|c|c|c|}
\hline Faculty & \multirow{2}{*}{} & \multicolumn{2}{|c|}{ 2008/2009 } & \multicolumn{2}{|c|}{$2009 / 2010$} \\
\cline { 3 - 6 } & & $\mathbf{M}$ & $\mathbf{S D}$ & $\mathbf{M}$ & SD \\
\hline Architecture & 87 & 3.83 & 0.83 & 3.90 & 0.68 \\
\hline Health Sciences & 226 & 4.17 & 0.58 & 4.04 & 0.61 \\
\hline Engineering & 365 & 3.85 & 0.73 & 3.86 & 0.63 \\
\hline Social Sciences and Humanities & 624 & 4.07 & 0.70 & 4.05 & 0.61 \\
\hline Natural Sciences & 104 & 3.80 & 0.75 & 3.89 & 0.67 \\
\hline Total & 1406 & 3.99 & 0.71 & 3.98 & 0.63 \\
\hline
\end{tabular}

Significant differences were found by faculty after controlling for year $(F(4,1401)=11.47, p<0.001$, $\eta p 2=0.03$ ), as seen in Table 5. Figure 4 presents the results. 


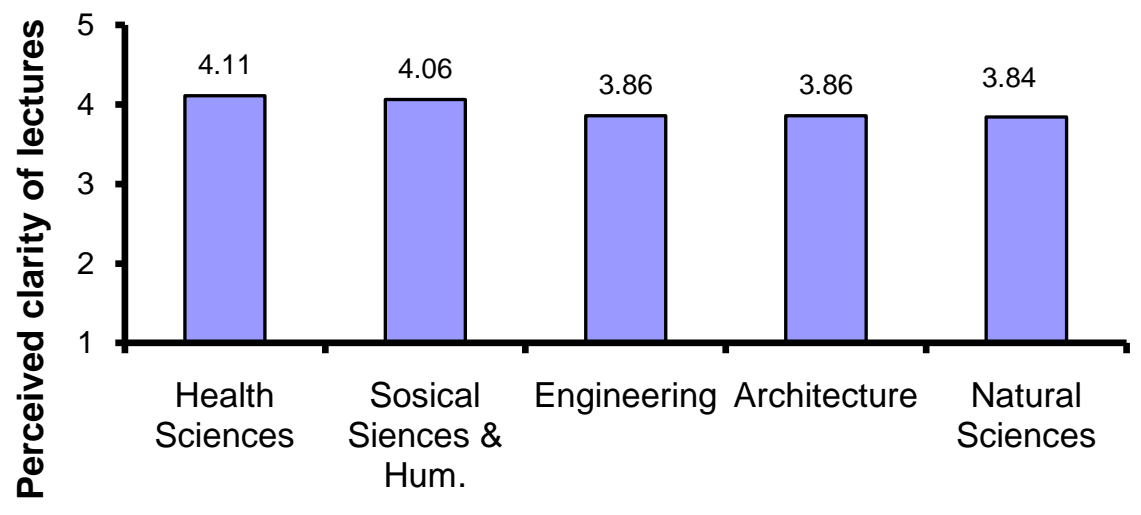

\section{Faculty}

Figure 4: Assessments of Lecture Clarity by Faculty

Findings show that ratings of lecture clarity were higher in the Faculty of Health Sciences and the Faculty of Social Sciences and Humanities than in the Faculty of Engineering, the School of Architecture, and the Faculty of Natural Science. An interaction by year and faculty was also found $(F(4,1401)=3.47, p<0.01, \eta p 2=0.01)$. To examine the source of the interaction effect, the difference in lecture clarity assessments comparing 2008/2009 and 2009/2010 was calculated. Figure 5 presents the results.

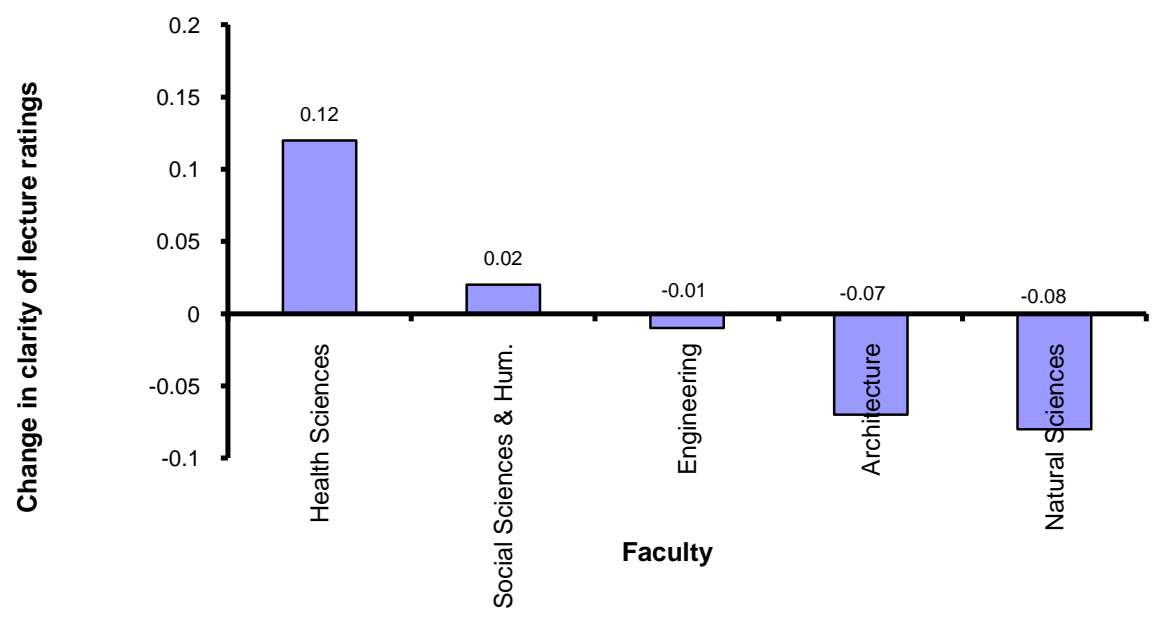

Figure 5: Changes in Assessments of Lecture Clarity by Year and Faculty

Differences in ratings of lecture clarity were found only between the School of Health Sciences and the Faculty of Natural Sciences. Assessments of lecture clarity increased in the Faculty of Health Sciences and ratings of lecture clarity by students in the Faculty of Natural Sciences decreased.

4. In Table 6, significant differences were found by year $\left(F(1,1405)=13.60, p<0.001, \eta_{p}{ }^{2}=0.01\right)$. In 2008/2009, ratings of instructors' encouragement of students to ask questions were higher than in 2009/2010. No interaction effect was found by faculty and year $(\mathrm{F}(4,1405)=2.67$, ns). 
Table 6: Means and SD - Encouraging Students to Ask Questions by Year and Faculty

\begin{tabular}{|c|c|c|c|c|c|}
\hline \multirow[t]{2}{*}{ Faculty } & \multirow[t]{2}{*}{$\mathbf{N}$} & \multicolumn{2}{|c|}{$2008 / 2009$} & \multicolumn{2}{|c|}{$2009 / 2010$} \\
\hline & & $\mathbf{M}$ & SD & M & SD \\
\hline Architecture & 87 & 4.02 & 0.76 & 4.04 & 0.55 \\
\hline Health Sciences & 230 & 4.45 & 0.57 & 4.30 & 0.49 \\
\hline Engineering & 365 & 4.09 & 0.69 & 4.03 & 0.55 \\
\hline Social Sciences and Humanities & 624 & 4.34 & 0.56 & 4.23 & 0.50 \\
\hline Natural Sciences & 104 & 4.18 & 0.61 & 4.14 & 0.57 \\
\hline Total & 1410 & 4.26 & 0.63 & 4.17 & 0.53 \\
\hline
\end{tabular}

Significant differences were found by faculty, controlling for year $(F(4,1405)=20.53, p<0.001, \eta p 2=0.06)$. Table 6 and Figure 6 present the results.

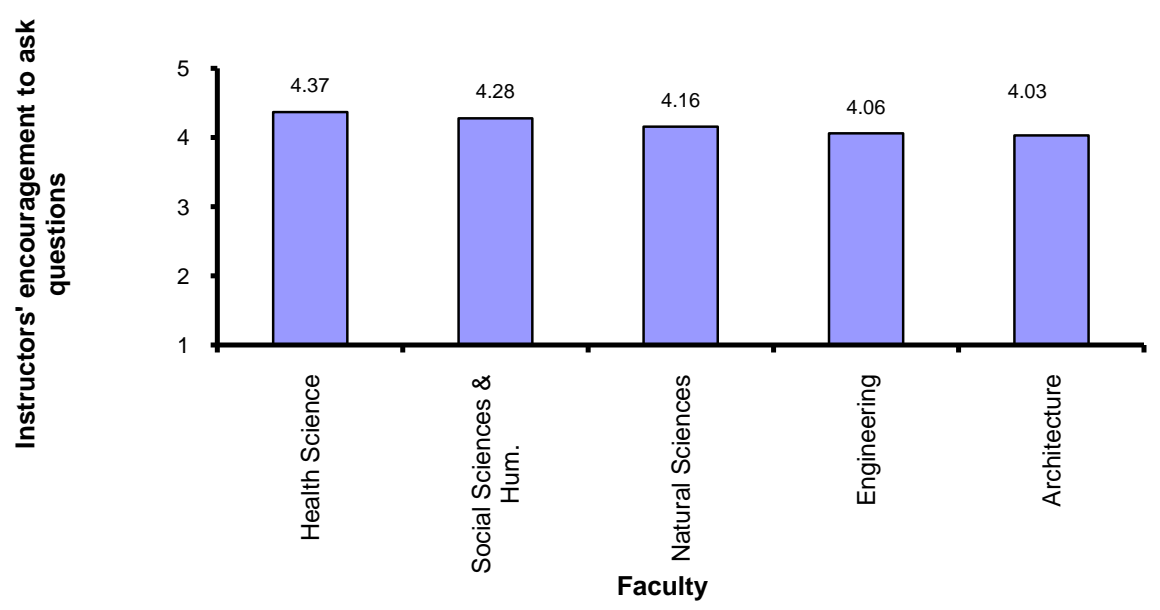

Figure 6: Instructors' Encouragement to Ask Questions

Students in the Faculty of Health Sciences and the Faculty of Social Sciences and Humanities awarded higher ratings to instructors' encouragement to ask questions compared to students in the Faculty of Natural Sciences, Faculty of Engineering, and School of Architecture.

5. Table 7 reflects the differences in students' ratings of instructors' attitudes toward students by faculty and year. No significant differences were found by year and no interaction effect was found by faculty and year.

Table 7: Means and SD - Instructors' Attitudes toward Students by Year and Faculty

\begin{tabular}{|l|c|c|c|c|c|}
\hline Faculty & \multirow{2}{*}{} & \multicolumn{2}{|c|}{ 2008/2009 } & \multicolumn{2}{|c|}{$2009 / 2010$} \\
\cline { 3 - 6 } & & $\mathbf{M}$ & $\mathbf{S D}$ & $\mathbf{M}$ & SD \\
\hline Architecture & 87 & 4.04 & 0.82 & 4.13 & 0.59 \\
\hline Health Sciences & 230 & 4.49 & 0.60 & 4.42 & 0.45 \\
\hline Engineering & 365 & 4.23 & 0.65 & 4.13 & 0.56 \\
\hline Social Sciences and Humanities & 624 & 4.39 & 0.56 & 4.31 & 0.50 \\
\hline Natural Sciences & 104 & 4.33 & 0.58 & 4.28 & 0.56 \\
\hline Total & 1410 & 4.34 & 0.62 & 4.27 & 0.53 \\
\hline
\end{tabular}

Significant differences were found by faculty after controlling for year $(F(4,1405)=16.55, \mathrm{p}<0.001$, $\eta \mathrm{p} 2=0.05)$. Table 7 and Figure 7 present the results. 


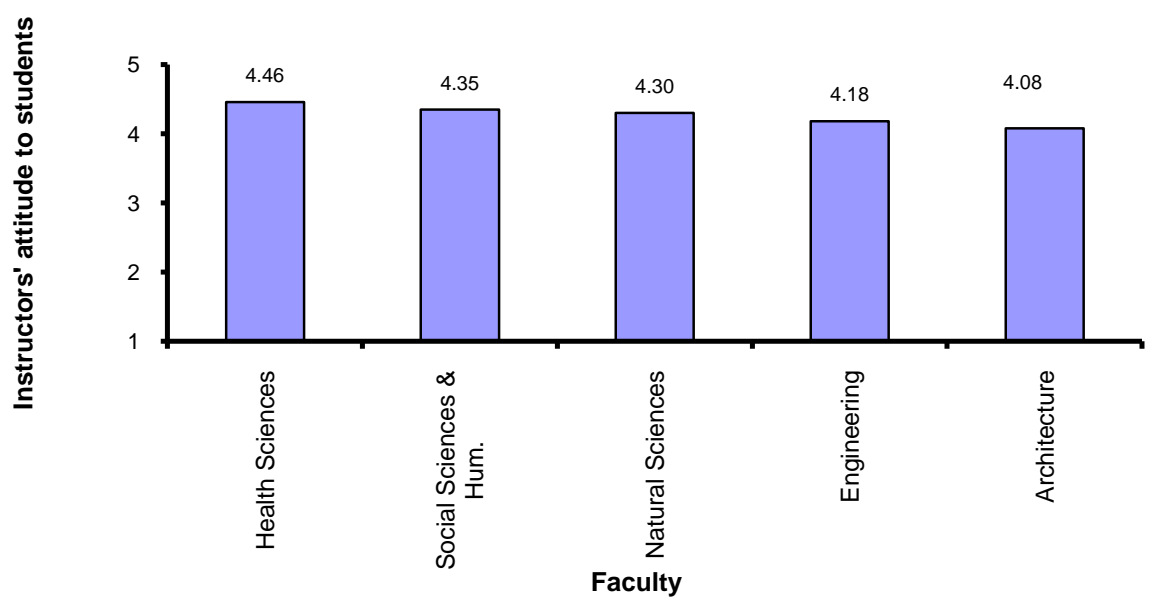

Figure 7: Instructors' Attitudes toward Students by Faculty

Students in the Faculty of Health Sciences awarded higher ratings to instructors' attitudes toward students than students in other faculties. Students in the Faculty of Social Sciences and Humanities and the Faculty of Natural Sciences awarded higher ratings to instructors' attitude toward students compared to students in the Faculty of Engineering and the School of Architecture.

6. Table 8 shows the differences in ratings of correspondence between lectures and tutorials by faculty and year. Significant differences were found by year $\left(\mathrm{F}(1,1312)=12.78, \mathrm{p}<0.001, \eta_{\mathrm{p}}{ }^{2}=0.01\right)$. Students' ratings of the correspondence between lectures and tutorials were higher in 2008/2009 compared to students' rating in $2009 / 2010$. No interaction effect by faculty and year was found $(F(4,1312)=2.08$, ns).

Table 8: Means and SD - Correspondence between Lectures and Tutorials by Year and Faculty

\begin{tabular}{|l|c|c|c|c|c|}
\hline Faculty & \multirow{2}{*}{} & \multicolumn{2}{|c|}{ 2008/2009 } & \multicolumn{2}{|c|}{$2009 / \mathbf{2 0 1 0}$} \\
\cline { 3 - 6 } & & $\mathbf{M}$ & $\mathbf{S D}$ & M & SD \\
\hline Architecture & 86 & 4.04 & 0.96 & 4.00 & 0.70 \\
\hline Health Sciences & 203 & 4.46 & 0.57 & 4.26 & 0.53 \\
\hline Engineering & 362 & 4.02 & 0.83 & 3.95 & 0.62 \\
\hline Social Sciences and Humanities & 562 & 4.32 & 0.77 & 4.15 & 0.63 \\
\hline Natural Sciences & 104 & 4.05 & 0.78 & 4.03 & 0.67 \\
\hline Total & 1317 & 4.22 & 0.79 & 4.09 & 0.63 \\
\hline
\end{tabular}

Significant differences were found by faculty after controlling for year $(F(4,1312)=18.98$, $p<0.001$, $\eta \mathrm{p} 2=0.06$ ). Table 8 and Figure 8 present the results. 




Figure 8: Ratings of Correspondence between Lectures and Tutorials by Faculty

Students in the Faculty of Health Sciences awarded higher ratings to the correspondence between lectures and tutorials than students in other faculties. Students in the Faculty of Social Sciences and Humanities awarded higher ratings to the correspondence between lectures and tutorials than students in the Faculty of Natural Sciences, School of Architecture, and Faculty of Engineering.

\section{CONCLUSION}

To summarize the findings, we note that no significant differences were found between the ratings awarded to the same instructors in 2008/2009 and 2009/2010. Differences in ratings were found by faculty in specific items:

1. Overall ratings of instructors were higher in the Faculty of Health Sciences compared to ratings by students in the School of Architecture, Faculty of Engineering, Faculty of Social Sciences and Humanities, and the Faculty of Natural Sciences.

2. Ratings of course structure and organization were higher in the Faculty of Health Sciences compared to ratings by students in the School of Architecture, Faculty of Engineering, and the Faculty of Natural Sciences. Ratings of course structure and organization were lowest in the School of Architecture. Ratings of course structure and organization in the Faculty of Social Sciences and Humanities were higher than ratings in Faculty of Engineering.

3. Ratings of lecture clarity were higher in the Faculty of Health Sciences and in the Faculty of Social Sciences and Humanities compared to the Faculty of Engineering, School of Architecture, and Faculty of Natural Sciences. A change in ratings of lecture clarity was found only in the Faculty of Health Sciences (ratings increased) and the Faculty of Natural Sciences (ratings decreased).

4. Ratings of instructors' encouragement of students to ask questions were higher in 2008/2009 compared to 2009/2010. Ratings in the Faculty of Health Sciences and in the Faculty of Social Sciences and Humanities were higher than in the Faculty of Engineering, School of Architecture, and Faculty of Natural Sciences.

5. Ratings of instructors' attitudes toward students were higher in the Faculty of Health Sciences than in other faculties. Ratings in the Faculty of Social Sciences and Humanities were higher than in the Faculty of Engineering and the School of Architecture. 
6. Ratings of the correspondence between lectures and tutorials were higher in 2008/2009 than in 2009/2010. After controlling for these differences, significance differences were also found by faculty: Ratings were higher in the Faculty of Health Sciences than in other faculties; i.e., ratings in the Faculty of Social Sciences and Humanities were higher than in the Faculty of Engineering, Faculty of Natural Sciences, and the School of Architecture.

\section{DISCUSSION}

In this study, we sought to examine the concern that defining participation in student surveys as a mandatory rather than optional task might have an adverse affect on thee authenticity of instructors' performance ratings. Individuals from both sides of this argument claimed that there is a potential for such adverse impact on ratings as a result of the coercion factor. In western societies that venerate individual rights, individualism, and free choice, and that view students as consumers whose needs should be satisfied (Marsh, 1987; Marsh \& Roche, 1994), such an organizational change is not always welcomed. In contrast to the academic consensus that assessment surveys should not be mandatory, due to their potential to be used as a means of revenge by students, the AUC decided to make a pioneering effort and link the privilege and the duty of this task. Imposing this requirements is not a draconian law, but rather a decision that was made after much deliberation, in view of the significant importance attributed to students' feedback and in view of the perception of students as a significant factor in creating "good teaching" (Ballantyne et al., 2000). As an institution that invests much effort in promoting and improving students' welfare, student surveys are merely the least that students could do to participate in these efforts in an act that was ultimately designed to improve students' learning environment.

Obtaining students' participation was not an easy task. On one hand, giving student the optional right to complete a survey generated a low response rate, and it created concerns that responses represent a homogeneous sample that fails to represent the opinions of the entire student body. On the other hand, defining participation as a mandatory requirement raised concerns that the responses would not be authentic. The findings of this study refuted these concerns.

Findings of this study prove that in view of the lack of significant differences in the ratings awarded to the same instructors in 2008/2009 and 2009/2010, there should be no concerns of bias originating in students' affiliation with specific faculties (in the case of voluntary participation) or students' attempts to retaliate against the system (in the case of mandatory participation). We may assume that those students who viewed mandatory participation in the survey as an act of coercion and opposed it, chose to express their opposition by partially completing the survey. Twenty percent of the students submitted a partially completed survey, which proves that most of the students were persuaded by the importance of the survey and took this task seriously.

Examining the findings on a faculty by faculty basis generates a clearer picture of reality and shows that differences in assessments emerge in certain items - clarity of lectures, instructors' attitudes, instructors' encouragement of students to ask questions, and correspondence between lectures and tutorials. Where such differences were found, ratings increased from the year of voluntary participation to the year of mandatory participation. This finding reinforces the argument that the imposition of this requirement did not have an adverse impact on assessments of instructors' performance, and rather, that the opposite is true. Statistically, the increase can be explained by a statistical cancellation of truncation (of the variance that reduces the correlation). Sampling the entire student body contributions to a normal distribution of assessment increased variance, and improved correlations. The only assessments that showed a decline in ratings in the study period were the assessments of clarity of lectures rated by students in the Faculty of Natural Sciences.

The findings of the study, especially in view of the sample size, indicate that the concerns surrounding the imposition of mandatory survey participation were not justified. When the task is mandatory, students' responses to the survey are dictated by their beliefs and opinions. We should further recall that posting of the survey was accompanied by an extensive informative campaign which explained the reasons for organizational change to the students. We tend to believe that when an appeal is directed to individuals' common sense and logic, they are ultimately persuaded. 
Linking the privilege and the requirement did not frustrate or embitter the students, as some predicted. The opposite is true. It seems that when students realized that there was no escaping participating in the survey, and when they recognized its significance, they performed the task diligently. The legal aspect of this issue was also discussed, as well as whether the institution had the legal right to prevent students who failed to participate in the survey from sitting for their exams. To establish the legal legitimacy of this condition, the requirement was introduced as an amendment to the AUC Regulations. We believe that the growing significance and implications of the survey results require that we link the privilege and the requirement. This is not based on desire to limit students' free choice, but rather out of our respect for students' rights and recognition of the significance of students' participation in the assessment process.

\section{AUTHOR INFORMATION}

Dr. Nitza Davidovitch holds a doctorate degree, awarded by Bar Ilan University, focused on the developmental trends of regional colleges and their impact on the higher education system in Israel. Dr. Davidovitch currently heads the Department of Academic Development at Israel's largest public college, the Ari'el University Center, Israel.

Prof. Dan Soen earned the B.A in Oriental Studies at the Hebrew University, Jerusalem, 1955. Earned the Dr.Phil at the Vienna University, 1959 in Cultural Anthropology. Taught in various universities in Israel and abroad (NewZealand, South Africa and the USA). Served as Department Head in various academic institutions. Headed research institutions. Worked as senior consultant (in social planning as well as urban \& regional planning) to various ministries and the Jewish Agency in Israel. Worked as senior consultant in planning projects in Asia and Africa. Served as senior civil servant (CEO) in various bodies. Published about 30 books and around 120 articles on social problems both in Israel and abroad. Currently: Head of the Dept. of Sociology \& Anthropology and Chair of the Dual Major Dept., Ari'el University Center, Israel. Prof. at the Graduate School, Kibbutzim School of Education, Tel-Aviv

\section{REFERENCES}

1. Anderson, K.H \& Siegfried, J.J. (1997) Gender difference $s$ in rating the teaching of economics, Eastern Economic Journal, 23(3), 347-357.

2. Avador, S. (2006). For whom and for what? Bias factors in student's evolutions at educational colleges and the question of benefit for the evaluated and the organization, Dapim, 41, 10-37 (Hebrew version).

3. Ballantyne, R., Borthwick, J. \& Packer, J. (2000). Beyond student evaluation of teaching: identifying and addressing academic staff development. Assessment \& Evaluation in Higher Education, 25(3), 221 - 236.

4. Chandler, T. (1978). The questionable status of student evaluations of teaching. Teaching of Psychology, $5(3), 150-152$.

5. $\quad$ Chen, Y. \& Hoshower, L. B. (1998) Assessing student motivations to participate in teaching evaluations: an application of expectancy theory, Issues in Accounting Education, 13(3), 531-549.

6. Davidovitch, N. \& Notzer. N. (2004). Students' attendance and scores of teacher's evaluations, Al-Agova, 3, 38-41 (Hebrew version).

7. Ehie, I. \& Karathanos, D. (1994). Business faculty performance evaluation based on the new AACSB accreditation standards. Journal of Education for Business, 69 (5), 257-262.

8. Feldman, K. A. (1997). Identifying exemplary teachers and teaching: Evidence from student ratings. In R. P. Perry \& J. C. Smart (Eds.), Effective teaching in higher education: Research and practice (pp. 368-395). New York: Agathon.

9. Feldman, K. A. (1983). The seniority and instructional experience of college teachers as related to the evaluations they receive from their students. Research in Higher Education, 18, 3-124.

10. Feldman, K. A. (1978) Course characteristic s and college students' ratings of their teachers: what we know and what we don't. Research in Higher Education, 9(2), 199-242.

11. Fish, S. (2010): New York Times Opinions, 21.6. Internet: http://opinionator.blogs.nytimes.com/2010/06/21/deep-in-the-heart-of-exas/?src=me\&ref=general. Accessed: 13.9.2010. 
12. Harrison, P., Douglas, D., \& Burdsal, C. (2004). The relative merits of different types of overall evaluations of teaching effectiveness. Research in Higher Education, 45(3), 311-323.

13. Hativa, N. (2008). Myths and facts about evaluation surveys by students, Al-Hagova, 7, 13-14 (Hebrew version).

14. Hativa, N. (2003a). Do teachers at humanities and art are better than their colleagues at management and engineering? Al-Hagova, 2, 38-40 (Hebrew version).

15. Hativa, N. (2003b). What teachers should know and do-student's reform at teaching, Hed-Hachinoch, 6 , 14-19 (Hebrew version).

16. Hativa, N. (2002). New thought on university and college teaching: teaching as proficiency, Al-Agova, 1, 69 (Hebrew version).

17. Koermer, C. D. \& Petelle, J. L. (1991). Expectancy violation and student rating of instruction. Communication Quarterly, 39(4), 341-350.

18. Marsh, H. W. \& Roche, L. A. (1994). The use of students' evaluations of university teaching to improve teaching effectiveness. Final project report for the Evaluations and Investigations Program of the Department of Employment and Education. Canberra: Australian Government Printing Service.

19. Marsh, H. W. (1987). Students' evaluations of university teaching: Research findings, methodological issues, and directions for future research. International Journal of Educational Research, 11(3), $253-288$.

20. Marsh, H. W. \& Cooper, T. L. (1981). Prior subject interest, students' evaluations, and instructional effectiveness. Multivariate Behavioral Research, 16(1), 83.

21. Priestly, J. (2010): New York Times Opinions, 21.6. Internet: http://opinionator.blogs.nytimes.com/2010/06/21/deep-in-the heart-of-exas/?src=me\&ref=general. Accessed: 13.9.2010

22. Rindermann, H. \& Schofield, N. (2001). Generalizability of multidimensional student ratings of university instruction across courses and teachers. Research in Higher Education, 42(4), 377-399.

23. Smith, K. \& Pollak, M. W. (2008). What Can They Say about My Teaching? Teacher Educators' Attitudes to Standardised Student Evaluation of Teaching. European Journal of Teacher Education, 31(2), 203-214.

24. Tatro, C. N. (1995) Gender effects on students evaluation s of faculty, Journal of Research and Development in Education, 28(3), 169-173.

25. Wachtel, H. K. (1998) Student evaluation of college teaching effectiveness: a brief review, Assessment and Evaluation in Higher Education, 23(2), 191-211.

26. Worthington, A. (2002). The Impact of Student Perceptions and Characteristics on Teaching Evaluations: a case study in finance education. Assessment \& Evaluation in Higher Education, 27(1), 49-64.

27. New York Times: http://opinionator.blogs.nytimes.com/2010/06/21/deep-in-the-heart-ofexas/?src=me\&ref=general 